Bu makalenin amacı, gösterinin kavramsal çerçevesini ve mimarlık alanı üzerindeki etkisini ortaya koymaktır. Gösteri, Debord'un onu geçtiğimiz yüzyılın toplumunu tanımlamak için kullandığından beri, dikkat çekici ve etkili bir kavram olma özelliğini korumaktadır. Öyle ki, gösteri kavramı ve gösteri toplumu kuramı felsefe, sanat ve sosyoloji gibi alanlarla sınırlı kalmayıp başka birçok toplumsal alanda tartışma konusu olmaktadır. Mimarlık alanında da sıklıkla tartışılan gösteri, gösteri mimarlığı kavramının ortaya çıkmasına neden olmuş; geçtiğimiz yüzyılda olduğu gibi, bu yüzyılda da güncel mimarlık anlayışını oluşturmuştur. Bu nedenle, makalede, bugünün mimarlık dünyasında gösteri ve mimarlığa olan etkileri ele alınmıștır. Gelișmiș bilgisayar teknolojileri ve medya sayesinde gösterinin medyatik, hipnotik, ekstatik, dinamik, atmosferik, fetisistik, eksantrik, fotojenik, ikonik ve egosantrik gibi kavramlarla tanımlandığı ve tartışıldığ 1 anlaşılmıștır. Bu kavramlar, gösteriye ve gösteri mimarlığına yönelik eleştirel bir bakış açısının geliştirilmiş olduğunu ortaya koymaktadır. Eleștiri, gösterinin bugünün dünyasının gerçeği ve başlıca değeri olmasını engelleyememiş olsa da gösterișli bir biçimde tasarlanan ve tüketilmek üzere üretildiği anlaşılan mimarlık ürünlerine eleștirel bakabilmemizi sağlamaktadır. Belki de bu eleştirel bakıs açışı, bugünün mimarlığının yanı sıra bugünün toplumunu, kentini ve kültürünü de karakterize eden gösterinin önüne geçilmesine değilse de ehlileştirilmesine yol açacaktır. Gösterinin ehlileștirilmesiyle üretimi ve tüketimi arttırmak yerine bu ikisi arasındaki ilișkileri yeniden düzenleyerek dengede tutmak mümkün olacaktır. Böylece toplumsal bir üretim alanı olan mimarlıkta bireysel hırslardan ve aşırıya kaçmıș tüketim alışkanlıklarından uzaklaşılacak; gösteri(ş) yapmak değil topluma yarar sağlamak mimarlığın önceliği olarak görülmeye başlayacaktır.

Anahtar Kelimeler: Gösteri mimarlığı, gösteri toplumu, tüketim kültürü, kitle kültürü.

\section{Debord'un Gösteri Toplumu Kurami Üzerinden Bugünün Dünyası ve Gösteri Mimarlığı Üzerine Bir Eleştiri}

(D) Gülşah Güleç

Gazi Üniversitesi Mimarlık Fakültesi, Mimarlık Bölümü, Ankara, Türkiye

Başvuru tarihi/Received: 02.05.2021, Kabul tarihi/Final Acceptance: 24.10 .2021

\section{Extended Abstract}

Spectacle is still a challenging concept since it is used by Debord to define and discuss the status of the society in the $20^{\text {th }}$ century. As such, the concept of spectacle is discussed in many other social disciplines as the disciplines of philosophy, art and sociology. It is also discussed in the discipline of architecture in such a way that the concept of spectacular architecture is developed in the last century. This paper is based on the spectacular architecture and its consequences. The aim of the paper is to reveal the conceptual framework of spectacle and its recent effects in architecture. According to Debord, spectacle defines a society full of spectacular objects and images. Both objects and their images are commoditized in the society of the spectacle (See Debord, 1996). The commoditization process promotes the process of consumption. The images of the objects are even consumed during these processes. Hence, the production of the object is mainly replaced by the production of image in today's society. Images are easily and rapidly produced by using computer technology. They are commonly shared, experienced and consumed on media. So, spectacle becomes even more challenging in architecture and society.

Computer technology and media pave the way for the spectacle to enhance its effects throughout the world. Commercial is now the essential part of this world. Almost every product is commercialized today. Architectural products are also commercialized as any other industrial product. Media promotes these products together with their spectacular packages. Content already becomes irrelevant due to the fact that package is now more significant. Many architectural products have spectacular packages as well. Particularly their sophisticated facades turn them into spectacular products. They are seen as the most valuable products in the recent architecture. However, value does not only depend on spectacle or capital in architecture; it is also based on the social, environmental and cultural value of the architectural product.

Spectacle is the consequence of the capitalist economy policies. It now becomes more dominant in the big cities in which capitalist and neoliberalist economy policies are adapted. Big and spectacular buildings define the unique places and identities of these cities within the global world. Besides, spectacle turns them into touristic places. It points out to the fact that spectacle is especially for tourists and consumers. The culture of spectacle leads all of us to become tourists in our own cities. But cities are expected to enhance the sense of belonging. Architectural objects are also expected to be produced based on the real needs and requirements of the city-dwellers. They should not be produced to be spectacular objects or images. And such, this production process should not negatively affect the balance in between nature and architecture. But the big cities suffering from the big architectural productions and their costs lose their natural habitat day by day. They become bigger and bigger in such a way that they would recently meet other big cities and so the world would eventually turn into a giant city. Spectacle makes the world a whole, but a fragmented whole actually. This united and fragmented world is mainly discussed via Debord's theory of the society of the spectacle and today's spectacular architecture by the concepts such as mediatic, hypnotic, fetishistic, photogenic, iconic, dynamic, atmospheric, egocentric, eccentric and ecstatic in the paper.

Spectacular architectural products today are generally experienced by the city-dwellers as if they are tourists. Spectacle leads the relations of architecture and society to be disjunted. This disjunction is initiated within the industrial era of the $20^{\text {th }}$ century and it is enhanced within the digital era of the $21^{s t}$ century. It is critically discussed in the paper due to the fact that it sets architecture apart from the social needs, values, dynamics and realities. It is emphasized that spectacle both unites and fragmentizes today's world. Yet, it is a fact that spectacular architecture and the society of the spectacle would be even more effective and dominant in the future. Because today's political, financial and sociological conditions and technological opportunities would be more powerful in the world of the future. On the other side, not only spectacular images or image effects but also social needs and benefits should be significant for architects, designers, politicians, businesspeople and all the individuals in the society. We should redesign the relations in between architecture and society. We should balance the relations in between production and consumption as well. Architecture is actually a social production beyond our desires and consumption habits. It is about designing by thinking on encounters, spatial experiences and social relations. It is not a mere spectacular production.

Keywords: Spectacular architecture, the society of the spectacle, the culture of consumption, mass culture. 


\section{Giriş}

Bu makale, gösterinin kavramsal çerçevesini ve mimarlığı bir gösteri(s) alanına dönüştürecek kadar bu alan üzerinde kurduğu yönlendirici ve belirleyici etkiyi ortaya koymayı amaçlamaktadır. Makalede gösteri kavramı ve gösteri mimarlığı üzerine yapılmış ve literatürde öne çıkmış olan eleştirel tartışmalar yer almaktadır. Bunlar, gösterinin yalnızca mimarlık değil felsefe, sanat ve sosyoloji gibi alanlarda da tartışıldığını ortaya koymaktadır. 1967 yılında gösteri toplumu (the society of the spectacle) kuramını ortaya atan Debord, gösteriyi toplumu tanımlamak ve toplumsal değişimleri tartışmak üzere kavramsal bir araç olarak kullanmıştır. Gösteri, Debord'a göre, gösterişli nesnelerle ve imgelerle dolu bir toplumu tanımlamaktadır. Gösteri toplumunda imgeler ve imgeledikleri nesneler metalaşmış ve markalaşmıştır. Metalaşma ve markalaşma süreçleri, nesnelerin tüketilme sürecini hızlandırmıştır. Hatta nesneler yerine imgeleri tüketilmeye başlamıştır. Böylece üretim ve tüketim ilişkilerinde önemli bir değişim yaşanmıştır (Debord, 1996). Bugünün toplumunda nesne üretiminin yerini imge üretimi almış; imgelerin bilgisayar teknolojileri kullanılarak hızla ve kolaylıkla üretilmesi ve medya aracılığıyla dolaşıma çıkarılarak daha hızlı bir biçimde tüketilmesi, gösterinin toplum ve mimarlık üzerinde her zamankinden daha etkili olmasına yol açmıştır.

Bilgisayar teknolojileri ve medya, gösterinin etki alanını tüm dünyayı kapsayacak şekilde genişletmesini sağlamıştır. Reklam artık bu dünyanın ayrılmaz bir parçasıdır. Her şeyin reklamı yapılmaktadır. Mimarlık ürünleri reklamı yapılan herhangi bir endüstriyel ürün gibi pazarlanmaktadır. Medya, bu ürünleri gösterişli ambalajları ve içerikleri olan tüketim ürünleri olarak piyasaya tanıtmaktadır. Ancak ürünlerin içeriği ve işlevinden çok görünüşleri; yani paketleri, ambalajları ya da dış yüzleri ön planda yer almaktadır. Benzer bir durum, mimarlık ürünleri için de geçerlidir. Öyle ki, gösteri genellikle mimarlık ürünlerinin yüzeyinde gerçekleşmektedir. Bu ürünlerin gösterişli yüzeyleriyle hedef kitlesine ve müşterisine artı değer kazandıracă̆ vaat edilir. Ancak değerin sermaye ile ölçülmesi ve kullanıcının yerine müşterinin geçmesi, mimarlık ürününün toplumsal ve sanatsal değerinin göz ardı edildiğine işaret etmektedir.

Debord, gösterinin sermayenin birikimi olduğunu belirtir (Debord, 1996). Gösteri, kapitalizm ve neoliberalizm gibi ekonomi politikalarıyla birlikte sermayenin biriktiği büyük kentlerde daha da görünür hale gelmiştir. Büyük ve gösterişli yapılar, bu kentlerin küresel dünyadaki yerini ve kimliğini belirlemektedir. Bununla birlikte gösteri, kentleri turistik yerler haline getirmektedir. Başka deyişle, gösteri turiste ve genel olarak tüketiciye hitap etmektedir. Kentlerde gösteri kültürünün yaygınlaşması hepimizi birer turiste dönüştürmektedir. Oysa kentler, içinde yaşadığımız yerler olarak, aidiyet duygusunu güçlendirmelidir. Bunun için, kentlerde gösterişli mimarlık nesneleri ya da imgeleri üretmek yerine toplumun gerçek istek ve ihtiyaçlarına göre üretim yapılması gerekir. Ayrıca bu üretimin doğanın dengesini ve işleyişini bozmaması beklenir. Bu açıdan bakıldığında, büyüklüğün önemli bir sorun olduğu görülmektedir. Bugün büyük ölçekli yapılarla adeta yeniden inşa edilen, doğal çevresi her geçen gün biraz daha zarar gören ve yok edilen kentler öyle büyümüş ve genişlemiştir ki yakın bir gelecekte kentlerin birleşeceği ve tüm dünyanın devasa bir kente dönüşeceği belirtilmektedir (Dyckhoff, 2017). Dolayısıyla gösteri, Debord'un da dediği gibi, dünyayı birleştirmekte ve bütünleştirmektedir (Debord, 1996).

\section{Bugünün Dünyası ve Gösteri Mimarlı̆̆ı}

Gösteri, mimarlık için, yeni bir kavram değildir. Bu kavram, uzun yıllardır mimarlı̆̆ 1 karakterize etmektedir. Debord ise gösteriyi daha çok toplumu karakterize ettiği düşüncesiyle eleştirmiştir. Sitüasyonist Enternasyonal hareketin öncülerinden biri olan Debord, gösterinin modern toplumun kurucu öğesi olduğunu belirtmiştir. Öncüsü olduğu hareket, modern toplumun ve modern mimarlığın akılcılık ve evrensellik gibi söylemlerine karşılık şiirsellik ve bireysellik gibi özellikleri gündeme getirmiştir (Debord, 1996). Endüstri devrimiyle birlik- 
te ortaya çıkan yeni, ucuz ve hızlı üretim biçimleri, mimarlı̆̆g modernize ettiği gibi, toplumu da modernleştirmiştir. Ancak mimarlığın seri bir üretim alanına dönüşmesi, birbirinden farklı yerleri ve kültürleri ayn1laştırması ve standardize etmesi eleştirilere zemin hazırlamıştır. Yine de modern üretimle birlikte mimarlığın yeni bir kavramsal ve biçimsel dil edindiği anlaşılmaktadır. Cam, çelik ve beton gibi yeni malzeme ve yapı teknolojilerinin kullanılmasıyla, plan ve cephenin birbirinden ayrılması ve özgür kılınmasıyla, mimarlık üretiminin herhangi bir endüstriyel üretim gibi serileştirilmiş, mekanize ve standardize edilmiş olmasıyla ortaya çıkan modern mimarlık dili gerçekten de yeni bir dildir (Frampton, 1996). Bu dilin ortaya çıkmasını ve 20. yüzyılın dünyasına yayılarak toplumdan mimarlığa her şeyi yeni baştan oluşturmasını sağlayan modernizm, yalnızca yapılı çevreyi değil bütünüyle gündelik yaşamı ve alışkanlıkları değiştirmiştir. Böylece üretim ve tüketim biçimleri de değişim geçirmiştir.

Mimarlık alanında olduğu gibi hemen her toplumsal alanda üretimin hız kazanmış olması tüketimi de hızlandırmıştır. Tüketimin zamanla gerçek istek ve ihtiyaçlardan bağımsız hale gelmesi ise üretim ve tüketim ilişkilerinin değişmesini kaçınılmaz kılmıştır. Bu değişim, tüketimin öncelikli bir toplumsal etkinliğe dönüşmesine ve modern toplumları ele geçirmesine yol açmıştır. Baudrillard bunu tüketim toplumu olarak adlandırmıştır (Baudrillard, 2008). Toplumsal bir alan olan mimarlıkta da tüketim, mimarlık üretiminin başlıca itici gücü olmuştur. Hatta mimarlık ürünleri artık tüketilmek için üretiliyor gibi görünmektedir. Adorno'nun belirttiği gibi, kültürün bile endüstrileștiği ve herhangi bir endüstriyel ürün gibi tüketildiği düşünülürse mimarlık ürününün de tüketilmesi şaşırtıcı değildir (Adorno, 2020). Urry, bu gelişmeyi kültürün ve ticaretin iç içe geçmesi; toplumsal ve kültürel yaşamın tüm yönlerini pazarlaştırmaya yönelik görünür bir istek olarak değerlendirmiştir (Urry, 1999).

Tam da bu istek dolayısıyla bugünün dünyasında mimarlık, çağdaş tüketim kalıpları içinde üretilen, toplumsal göstergeler sis- temi içinde dolaşıma çıkarılan ve tüketilen bir nesne haline gelmiştir. Hatta, Yırtıcı'ya göre, mimarlıktaki -izm'ler kalabalığı da tüketim ilişkilerinin bir yansıması olarak görülebilir (Yrttcc, 2005). Son yıllarda ise -izm'lerle tanımlanamayacak ve tartışılamayacak kadar çok çeşitli yaklaşımları bünyesinde barındıran mimarlığın her zamankinden daha gösterişli bir üretim alanına dönüştüğü görülmektedir. Buna bağlı olarak, mimarlık toplumsal bir alan olmaktan giderek uzaklaşmaktadır. Mimarlığın artık onu talep etme ve satın alma gücü bulunan çevreler için tüketim nesnesi; diğerleri içinse seyirlik nesne ürettiği anlaşılmaktadır. Bu yüzden, mimarlıkta bir nesne krizi (the crisis of the object) yaşanmaktadır. Hartoonian, bu krizin başlıca nedenini mimarlı̆̆ın bir gösteri alanına dönüşmüş olması olarak açıklamaktadır (Hartoonian, 2012).

\section{Bir Gösteri(s) Alanı Olarak Mimarlık}

Gösteri mimarlığı, gösteri toplumunun ürünü olarak karşımıza çıkmaktadır. Debord, gösteri toplumunu çok daha önce ortaya koymuş olsa da gösteri bugünün toplumunu da tanımlamaktadır (Debord, 1996). Ayrica Baudrillard'ın ortaya koyduğu tüketim toplumunun da bugün hala geçerli bir toplum modeli olduğu anlaş1lır (Baudrillard, 2008). Aslında bu toplum modellerini (gösteri toplumипи ve tüketim toplumunu) birbirinden ayrı düşünmemek gerekir; çünkü gösteri tüketimi, tüketim de gösteriyi içerir. Debord, gösteri toplumunda nesnelerden çok imgelerin tüketildiğini belirtir. Gösteri toplumunda imge, imgelediği nesnenin önüne geçmiştir. Dahası, nesneden bağımsız hale gelmiştir. Debord, buna özerkleşmiş imge dünyası demiştir. Bu dünyada gerçek nesneler sanal imgelere dönüşmekte; imgeler, nesnelerden daha gerçekmiş gibi görünmektedir (Debord, 1996). Bu da yeni bir gerçekliğe ve yeni bir estetiğe, Virilio'nun deyişiyle, kayboluş estetiğine işaret etmektedir. Virilio'ya göre, nesnenin yerini imgesi aldığ 1 için nesne kaybolmuştur. Artık tek bir gerçeklik vardır; onun da gösterişli imgelerin gerçekliği olduğu açıktır (Virilio, 1991).

Gösteriyle birlikte gelişen yeni estetik ve gerçeklik anlayışı her ne kadar görmeyi diğer duyulara göre üstün kılmış olsa da 
görme en soyut ve en aldanabilir duyu olarak nitelendirilir. Bu nedenle, görmeden ziyade dokunma duyusunun gerçeklik algısında önemli olduğu belirtilmiştir. Pallasmaa, mimarlıkta gözün öncelikli duyu organı olmasını patolojik bir durum olarak değerlendirmiştir. Bu durum, mimarlığ anlık olarak oluşturulmuş görsel bir imge repertuarı haline getirmiştir (Pallasmaa, 2016, 171-189). Bugünün bilgisayar teknolojileri ise anlıksallığı ve rastlantısallığı desteklemektedir. Bilgisayar ekranında anlık ya da rastlantısal olarak oluşturulan mimarlık imgeleri yine bilgisayar teknolojileri arac1lığıyla paylaşılmakta ve dolaşıma çıkarılmaktadır. Bunlar medyada çoğunlukla anlık ya da rastlantısal olarak gördüğümüz imgelerdir. Bu imgeler, son y1llarda mimarlığın belki de daha önce hiç olmadığ gösterişli bir üretim alanına dönüştüğünün birer göstergesi gibidir (Resim 1-2).

Mimarlıkta artık her geçen gün çok daha gösterişli olduğu görülen mimarlık imgeleri üretilmektedir. İmgeler, sanal mimarlık platformlarında ve sosyal medyada sıklıkla paylaşılmaktadır. Mimarlık imgelerinin paylaşım ve dolaşım ağı, bu imgeleri ve tasarımcılarını medyatik hale getirmiştir. 1987 yılında 20 yıl önce ortaya koyduğu gösteri toplumu üzerine yeni yorumlarda bulunan Debord da gösteri kavramından çok medyatik kavramının kullanılmaya başladığına değinmiştir. Gösteri artık medyatik aşırılıklardan ibarettir. Teknoloji ise kazandığı hızla birlikte gösterinin otoritesini ve aşırı karakterini güçlendirmiştir ( $D e-$ bord, 1996). Böyle bir ortamda, mimarlığın gösterinin bir parçası; hatta başlıca üretim alanı olması kaçınılmaz gibi görünmektedir. Bu ortam, mimarlığı görsel bir alan olmaya indirgemiştir. Halbuki mimarlık, Pallasmaa'ya göre, aynı anda birden çok duyuya hitap etse de daha çok dokunsal bir alandır. Bu nedenle, Pallasmaa tenin gözleri olduğunu savunmaktadır. Mimarlık nesnesinin varlığ çekliği ancak dokunarak anlaşılır. Dokunarak değil yalnızca görerek deneyimlenen mimarlık nesnesinin gerçekliğinden şüphe duyulmalıdır (Pallasmaa, 2011, a).

Diğer yandan, mimarlık nesnesinin bugün daha çok imgesi üzerinden deneyimleniyor olması, mimarlık imgesini imgelediği nesneyi temsil etmenin ötesine taşımıştır. Böylece yeni bir gerçeklik anlayışı ortaya çıkmıştır. Bu anlayış, imgeyi bir medya inşası olarak değerlendiren; bununla birlikte, mimarlık imgesinin de en az mimarlık nesnesi kadar gerçek olduğunu belirten Rattenbury'nin ifadesiyle, imgenin gerçekliğini vurgulamaktadır (Rattenbury, 2002). Debord da gösterinin görünür kıldığı dünyanın imgelerin ve metaların dünyası olduğunu ortaya koymaktadır. Debord'a göre, gösteri artık öyle bir birikim aşamasındaki sermayedir ki imge haline gelmiştir. İmge, sermaye sayesinde, metalaşmıştır (Debord, 1996). Gösteri, imgenin metalaştı̆̆ının göstergesidir. Metalaşma, tıpkı reklamlarda olduğu gibi, imgelerin tüketicileri baştan çıkarmak, etkilemek, şaşırtmak ya da en azından onların ilgisini çekmek üzere oluşturulduğu anlamina gelir (Saunders, 2005, vii-viii). Mimarlık imgelerinin de metalaştığı görülmekte-
Ulusal Kütüphane, BIG Architects, Astana, Kazakistan, 2009 (URL-I).
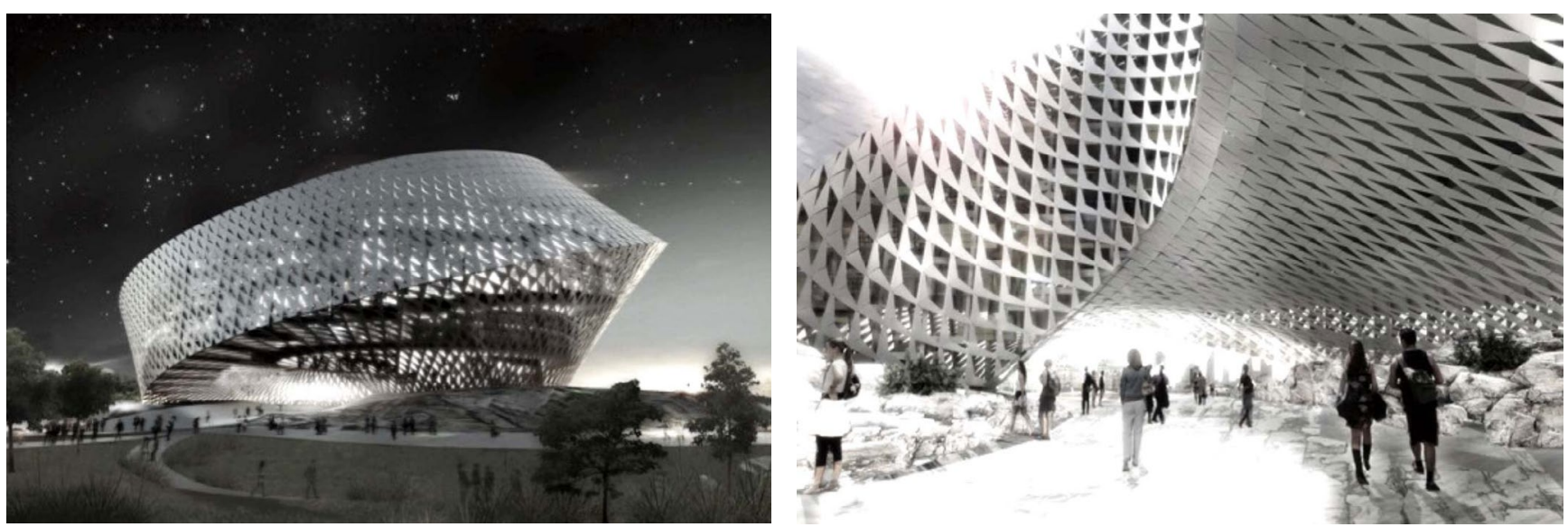
dir. Öyle ki, metalaşma süreci mimarlığı bir gösteri ve eğlence sektörüne (architecture + entertainment $=$ architainment ) dönüştürmektedir (Galiano, 2005, 1-7). Mimarlıkta metalaşma ve markalaşma süreçleri birbirini izlemektedir (Resim 3). Bu süreçler, mimarlığın bir sektör olmanın ötesinde bir pazar olduğuna işaret etmektedir (Sorkin, 2005, 22-33).

Dolayısıyla mimarlık ürünü bir pazarlama ürünü haline gelmiştir. Artun'a göre, bu durum 1980li yılların "anything goes" olarak özetlenen mimarlık anlayışıyla birlikte kendisini göstermiştir (URL-3). Mimarlıkta her şeyin gerçekleştirilebilir ve kabul edilebilir olduğunu ifade eden bu anlayışın 1990lı ve 2000li yıllarda da geçerliliğini koruduğu görülmektedir (Dyckhoff, 2017). Bunu dünyaca ünlü mimarların Dubai'de ve Pekin'de ortaya koydukları mimarlık ürünleri açıkça örneklemektedir. Buchanan, bu ürünleri star mimarların (star architects) ve star mimarlıkların (star architectures ya da starchitectures) içi boş gösterileri olarak değerlendirmektedir. Özellikle son yıllarda dinamik biçimlerin yarattığı anlık etki ve heyecana dayalı bir mimarlığın ortaya çıktığından söz etmektedir. Buchanan, bu dinamik mimari biçimlerin yeriyle ve dışarının içeriyle hiçbir ilişkisinin olmadığını belirtir (Resim 4, 5). Bu nedenle, mekânlar gelişigüzel ve rastlantısal olarak ortaya çıkmaktadır. Mimarların artık böyle anlık heyecanlar yaratmak üzere benimsedikleri egosantrik tasarım anlayış1$\mathrm{n} 1$ bir yana birakması gerekir. Yine de bunlar, Buchanan'a göre, egosantrik oldukları kadar eksantrik de olan tasarımlardır; ancak yeri ya da işlevi değil mimarlarının bireysel

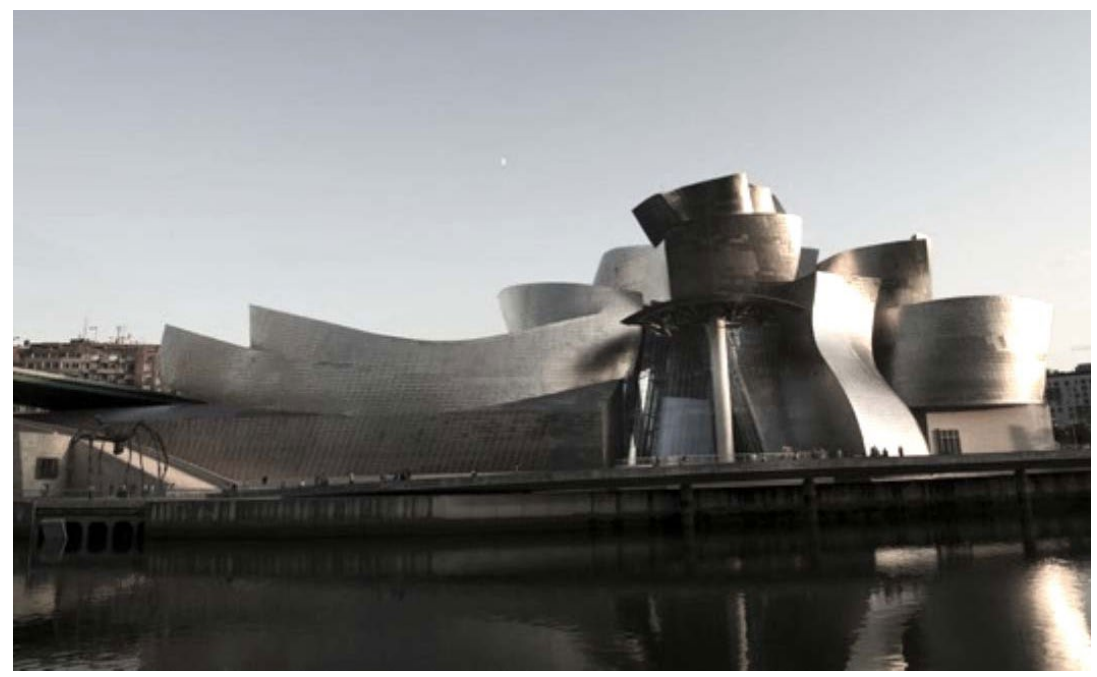

beğenilerini ve beklentilerini yansıtmaktadır (URL-4).

$\mathrm{Bu}$ anlayış, Debord tarafindan, fetişizimle ilişkilendirilerek tartışılmıştır. Gösteri artık her yerdedir ve fetişizme hizmet etmektedir. Burada eleştirel bir bakış açısıyla tartışılan imge ve meta fetişizmidir. Metalaşan imgeler (buna mimarlk imgeleri de dahildir) yalnızca pazarlanmakla ya da alınıp satılmakla kalmaz aynı zamanda fetişistik öğeler haline getirilir (Debord, 1996). Bugün içinde bulunduğumuz dijital çağda her türlü ürünün, imgenin ve deneyimin görselleştirildiğini ve reklamlar, sosyal medya ya da internet ağı aracıllığıla birer meta haline getirildiğini düşünürsek gösterinin bu çağı istila etmiş olduğunu anlamak çok da zor değildir. Bilgi ve iletişim ağı, bugünün dünyasını küresel bir üretim ve tüketim ortamı haline getirmiştir. Bu ortam içerisinde yerden ya da kültürden bağımsız olarak hemen
Resim: 3

Guggenheim Müzesi, Frank Gehry, Bilbao, Ispanya, 1997 (URL-2). Mimarlik literatüründe bu müze yarattığı Bilbao Etkisi (Bilbao Effect) ile tartısıllir. Guggenheim Müzesi, Bilbao'yu dünyaca ünlü bir kent haline getirmiştir. Gehry'nin ise mimarlık stilinin en ünlü imgelerinden biridir.
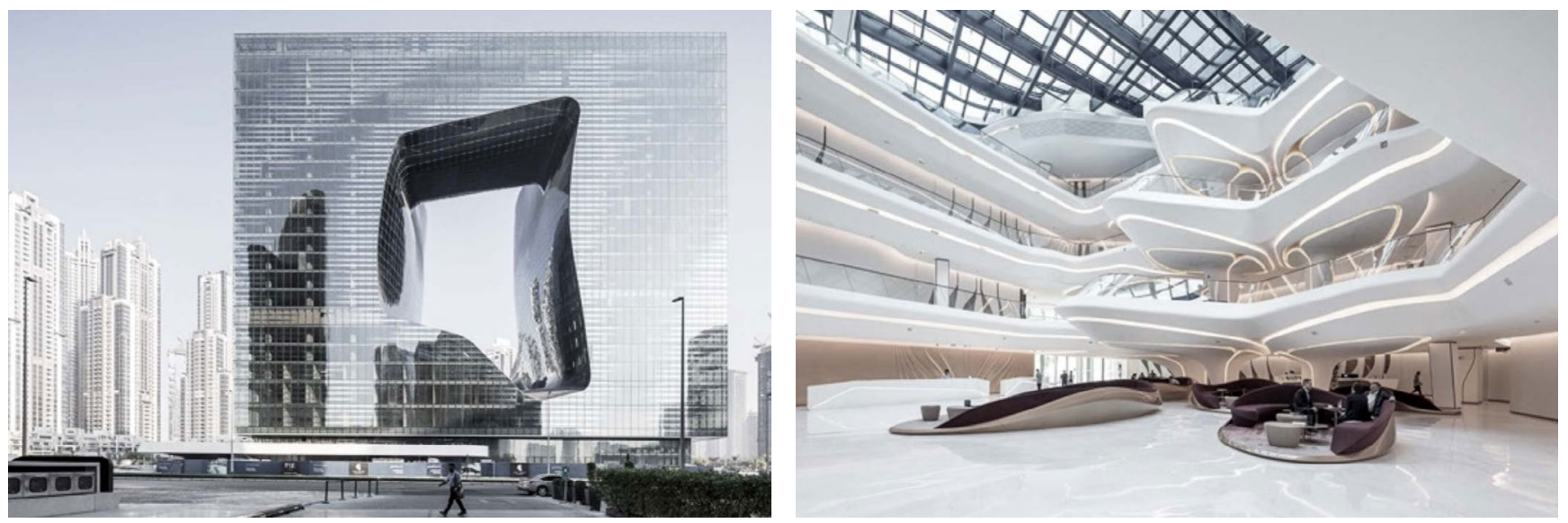
Resim: 6

Pekin 2050, MAD Architects, f̧in, 2018 (URL-6).

Resim: 7

Maden Müzesi, Peter Zumthor

Allmannajuvet, Norves, 2016 (URL-7).

Zumthor'un mimarlığı, Pallasmaa'nın makalelerinin de etkisiyle, literatürde

genellikle kirılgan ya da dokunsal mimarlık olarak adlandirilir. hemen her yerde aynı nesneler ve imgeler üretilmektedir. Mimarlık da bu kitlesel ve küresel üretim ortamının bir parçası gibi görünmektedir. Mimarlık nesneleri ve imgeleri daha çok anlık etki yaratmak üzere üretilmektedir (Resim 6). Bu nedenle, hızla ve kitlesel iletişim ağı aracılığgyla tüketilmektedir. Tüketim öyle bir boyuta gelmiştir ki yalnızca mimarlığın değil kentin de yeniden kavramsallaştırmasını gerektirmiştir.

Öyle ki, cityscape ya da landscape gibi kavramlar yerine artık brandscape kavramından söz edilmektedir. Bu kavramsal değişimin arkasında ekonomi politikalarında yaşanan değişim bulunmaktadır. Küresel ekonomiyi bugün kapitalizmden çok neoliberalizm olarak adlandırılan ekonomi politikaları belirlemektedir. Neoliberalizm, kapitalizmin kent ve mimarlık üzerindeki etkisinin artmasına yol açmıştır. Neoliberal ekonomi politikalarıyla kentler gösterişli mimarlık ürünleriyle donatılmakta ve soylulaştırılmakta; kentlerin peyzajı ve silueti gibi kimliği ve karakteri de değişime uğramaktadır (Güleç, 2019). Gösterişli kentte ya da gösteri kentinde her şey ikonik bir biçimde ve bizi etkilemek üzere tasarlanmaktadır. Bu nedenle, Dyckhoff mimarlıkta biçimin artık işlevi izlemediğini; biçimin işlevin kendisi olduğunu savunmaktadır (Dyckhoff, 2017).

2008 y1lında dünyada yaşanan ekonomik krizden sonra ikonik mimarlığın bittiği düşünülse de gerçekte gösteri mimarlığı olarak bugün de varlığını sürdürmektedir. Son dönemde ise gösteri mimarlığı yoğun bir biçimde eleştirilmektedir. Bu eleştirilerle birlikte anti-ikonik mimarlık (anti-iconic architecture), yavaş mimarlık (slow architecture), zayıf mimarlık (weak architecture), kırılgan mimarlık (fragile architecture) ve dokunsal mimarlık (tactile architecture) gibi alternatif mimarlık anlayışları geliştirilmiştir (Resim 7). Anti-ikonik mimarlık, ikonik olmayan; yavaş mimarlık, hızla tüketilmek üzere üretilmeyen; zayıf mimarlık, ikonik ya da gösterişli olmak yerine sakin, süssüz ve gösterişsiz bir tavır sergileyen; kırılgan mimarlık, büyük ve görkemli görünmeyen; dokunsal mimarlık ise görme duyusundan çok dokunma duyusuyla deneyimlenen bir mimarlığa işaret etmektedir. Ancak, Dyckhoff'a göre, gösteri karşıtı bu mimarlıklar bile zaman içerisinde başka tür bir gösteri tanımlar hale gelmiştir (Dyckhoff, 2017).

Hartoonian, bugünün gösteri mimarlığını tanımlarken gösterişli ve teatral kavramlarını birbirinden ayırmaktadır. Bugünün mimarlığının teatral olmanın ötesine geçtiğini ve gösteri mimarlığı haline geldiğini vurgulamaktadır. Şöyle ki, bir mimarlık nesnesinin teatral olarak nitelendirilebilmesi için yüzeyinin zanaat değeri taşıyacak şekilde işlenmesi; bu nesnenin yüzeyiyle bir performans ya da bir tür gösteri sergilemesi gerekir. Bugün ise gösteri yine özellikle mimarlık nesnesinin yüzeyinde gerçekleşmekle birlikte dijital zanaatın gelişmiş olması gösterinin niteliğini değiştirmiştir. Gelişmiş dijital teknolojiler sayesinde mimarlık nesnesi artık gösterişli bir nesne olarak tasarlanmamakta, adeta hesaplanmaktadır. Hesaplama sürecinde ise genellikle yerle ya da kültürle ilişki kurulmamaktadır. Oysa teatrallik, kültürle yakından ilişkilidir; çoğu
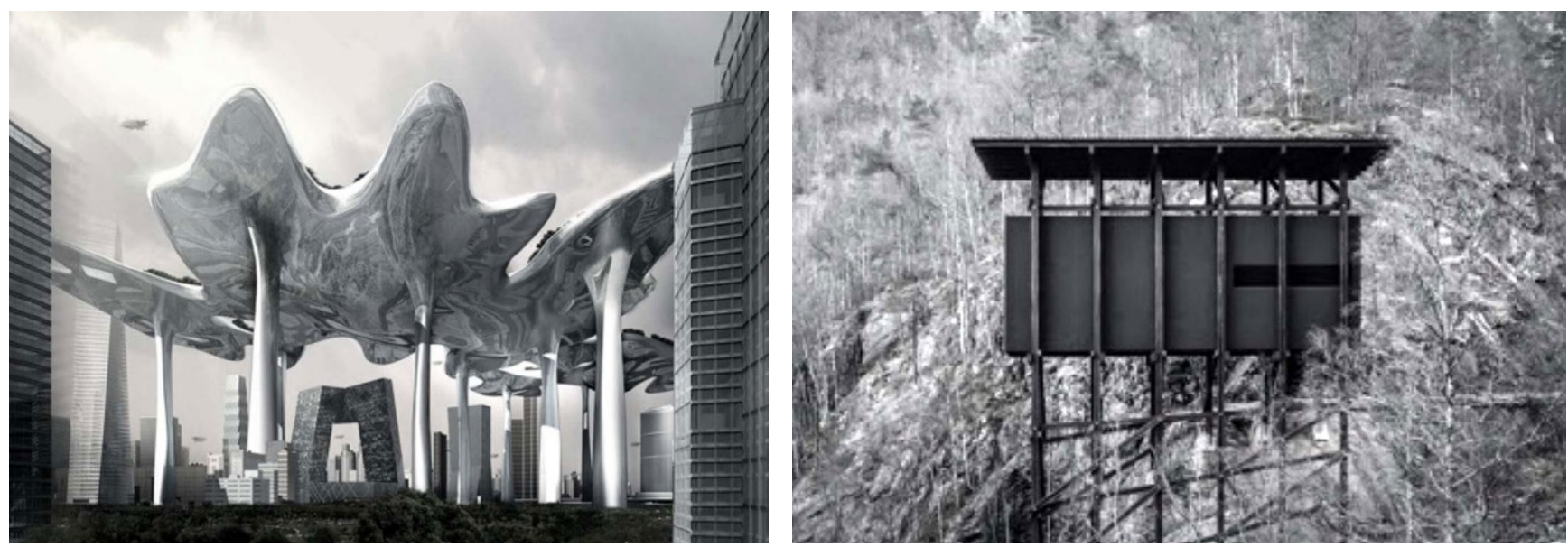
zaman teatral mimarlık nesnesinin kültürü temsil ettiği görülmektedir. Dolayısıyla bugünün mimarlığının teatral olmaktan çok gösteri mimarlığı olduğu belirtilmektedir. Mimarlık nesnesi artık kültürü değil kendisini temsil etmektedir. Gösterinin; başka deyişle, kendisini göstermenin peşindedir (Hartoonian, 2012).

Son yıllarda gösteri çoğunlukla mimarlık nesnesinin yüzeyinde; yüzeyin dijital teknolojiler ve medya teknolojileriyle bir gösteri ekranı haline getirilmesiyle ortaya çıkar. $\mathrm{Bu}$ teknolojiler, yüzeyde hipnotik bir etki yaratacak biçimde kullanılır (Resim 8). Dahası, yüzey zaman zaman optik bir yanılsamaya neden olmaktadır (Leatherbarrow, Mostafavi, 2002). Ancak mimarlı̆̆ın hipnotize edici bir yüzey tasarımına indirgenmesi çeşitli sorunlara yol açmıştır. Bunların başında, mimarlığın iki boyutlu bir imge tasarımı gibi algılanması gelir. Bu algılama biçimi, mekânın ve mekânsal deneyimin arka plana itilmesiyle birlikte gelişmiştir (Pallasmaa, 2011, b). Oysa mimarlık, her şeyden önce, bir mekân tasarımıdır. Hem diğer sanatlarla ilişki kurarak hem de onlardan farklı olarak insanlara mekânsal bir kullanım ve deneyim alanı sunmaktadır. Diğer yandan, gösteri mimarlığı, mimarlığın önceliklerini değiştirmiştir. İnsanlara yeni bir mekânsal deneyim yaşatmayı değil yeni bir biçimsel, yüzeysel ya da imgesel etki yaratmayı daha önemli hale getirmiştir. Bu, yalnızca toplumun ve mimarlığın değil aynı zamanda bütünüyle kültürel yapının değişmiş olduğuna işaret etmektedir. Gösteri kültürü artık kitle kültürü ve tüketim kültürü gibi diğer kültür tanımlamalarını da içine alacak ve bugünün dünyasına hâkim olacak kadar genişlemiştir. Debord, bunu kültürün yok oluşu olarak değerlendirmiştir; çünkü kültür, gösteri toplumunun en önemli metası haline gelmiştir (Debord, 1996). Endüstriyel devrimle birlikte ortaya çıkan gösteri kültürü, dijital devrimin yaşandığı bugünlerde belki de Debord'un bile hayal edemediği bir düzeye erişmiştir. Bilgisayar teknolojileriyle oluşturulan ve medya sayesinde dolaşıma çıkarılarak erişime ve paylaşıma açılan imgeler artık çok daha hızlı bir biçimde metalaşmakta ve markalaşmaktadır. $\mathrm{Bu}$ imgelerin, Deleuze'ün de belirttiği gibi, ekstatik bir etkisi bulunmaktadır (Deleuze, 1997). Mimarlık imgelerinin gerçekten de içinde bulunduğumuz bu son dönemde uyuşturucu, çeldirici ve hipnotize edici etkisine kapılmamak mümkün değildir. $\mathrm{Bu}$, aynı zamanda, atmosferik bir etkidir. Mimarlık imgesi, imgelediği nesneden bağımsız olduğu görülen bir atmosfer; yani, bir ortam yaratır ve izleyiciyi bu ortama dahil ederek kendisini onun bir parçasıymış gibi algılamasına olanak tanır (Wigley, 1998, 18-27). Ancak bu, bilgisayar destekli sanal bir ortamdir. Bu nedenle, sanal bir gerçeklik algısı oluşturmaktadır. Gösteri, bu yeni gerçeklik içerisinde, teknolojik olduğu kadar fotojenik de olan bir imge dünyasının ortaya çıkmasını sağlamıştır. Bu dünyanın bir parçası olan fotojenik mimarlık imgeleri, medya sayesinde, neredeyse üretilmeden önce tüketilmektedir (Colomina, 1988, 6-23). Gösteri ise medyatik tüketim sürecinin başlica hammaddesi olmaya devam etmektedir.

\section{Sonuç}

Bu makalede yer alan, mimarlık, felsefe, sanat ve sosyoloji gibi alanlarda yapılmış ve literatürde öne çıkmış olan tartışmalardan gösterinin geçtiğimiz yüzyıldan bugüne medyatik, hipnotik, ekstatik, dinamik, atmosferik, fetişistik, eksantrik, fotojenik, ikonik ve egosantrik gibi kavramlarla tanımlandığı ve tartışıldığı anlaşılmaktadır. Debord'un gösteri kavramını tartışırken bu kavramı toplumu tanımlamak üzere kullanmış ve başka birçok toplumsal alan gibi
Resim: 8

Uluslararası Kültür ve Sanat Merkezi, Zaha Hadid Architects, Çangşa, Çin, 2019 (URL-8).

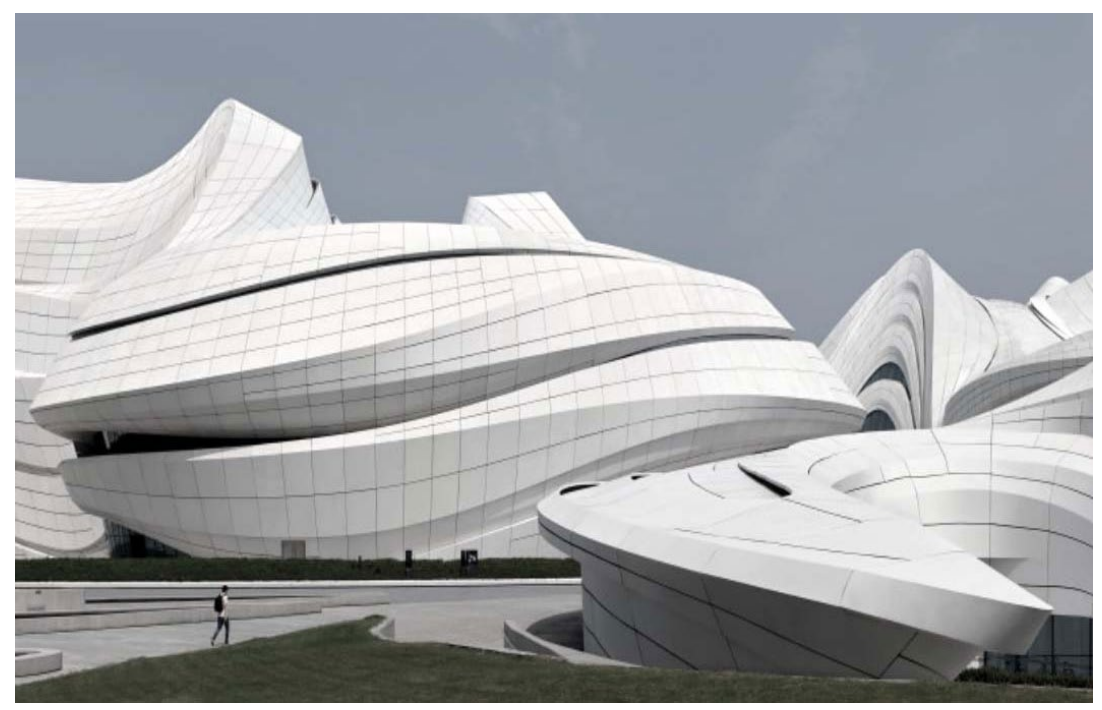


mimarlık alanını da yakından ilgilendiren, etkileyen ve dahası ifade eden bir kuram ortaya koymuş olması, gösteri toplumu kuramının bu tartışmanın odağında yer almasını sağlamıştır. Dolayısıyla toplumu tanımlamak için kullanılan gösteri kavramının aynı zamanda mimarlığ ortaya çıkmıştır. Bu kavram üzerinden ifade edildiği gibi toplumsal değerlerin, gerçeklerin ve dinamiklerin değişmesi, mimarlığı da değişime zorlamıştır. Kültür ise her ne kadar yerleşik kalıplara, geleneklere ve alışkanlıklara göre oluştuğu için değişmesi belki de en zor olan alan olsa bile toplumla ve mimarlıkla birlikte bu değişime ayak uydurmaktadır. Bu nedenle kitle kültürü (Adorno, 2020), tüketim kültürü (Baudrillard, 2008) ve gösteri kültürü (Debord, 1996) gibi farklı kültür tanımları ortaya çıkmıştır. 20. yüzyılın değişmekte olan kültürel ve toplumsal yap1sını tanımlayan bu kavramlar, 21. yüzyılda da hala geçerliliğini korumaktadır. Ancak, bu makalede, gösteri kavramının diğer kavramları da içine alacak şekilde genişlediği ve bu yüzyılın dünyasını istila ettiği vurgulanmaktadır. Özellikle büyük kentlerde sayıları her geçen gün artmakta olan büyük ve gösterişli yapılar, mimarlık ortamının yanı sıra toplumun da gösteriyi benimsediğini ya da en azından kabullendiğini ortaya koymaktadır. Bugünün dünyasında gösteri, bilgisayar teknolojileri ve medyanın da desteğiyle, küresel ve güncel bir toplum ve mimarlık modeli tanımlamaktadır.

Daha önce de belirtildiği gibi, gösteri dünyayı birleştirmiş ve bütünleştirmiştir. Bir dizi medyatik nesneler ve imgeler bütününe indirgemiştir. Ancak mimarlık, nesne ya da imge üreten bir alan olmanın ötesindedir. Ayrıca mimarlık ürünleri yalnızca tüketilmek üzere üretilmemektedir. Mimarlığın en temel üretimi olan mekân, bir tüketim nesnesi ya da gösterişli bir mimarlık imgesi değil kullanımın, karşılaşmaların ve deneyimin esas olduğu bir ortamdır.

Yine de bugünün gösteri mimarlı̆ğ, imgenin her zamankinden daha önemli ve etkili olduğunu ortaya koymaktadır. Bunun başlıca nedenlerinden biri, neoliberal ekonomidir. Neoliberal ekonomi, kentleri mimarlığın gösteri alanı haline getirmiştir. Büyük ve gösterişli yapılarla donatılan büyük kentler, sosyal medyada paylaşılan görüntülerle artık daha medyatik ve turistik yerlerdir. Bu kentlerde yaşayan insanlar bile birer turist gibidir. Mimarlığın toplumsal bir üretim alanı olmaktan uzaklaşıp bireysel bir üretim alanına dönüşmesiyle ve son dönemde özellikle lüks, devasa, gösterişli ve ulaşılmaz gibi görünen yapılar üretmesiyle birlikte insanlar bu yapıları deneyimlemekten çok seyretmekte ve fotoğraf makineleri ya da kameralarıyla görüntülemektedir. Oysa mimarlık, seyredilmek ya da görüntülemek için değil deneyimlemek için üretilmelidir. Mimarlık ürünlerinin toplum için; yani, toplum yararına ve toplumun katılımıyla üretilmesi gerekir. Ancak gösteri, üretim ve tüketim ilişkileri gibi mimarlık ve toplum arasındaki ilişkileri de birbirinden koparmıştır. 20. yüzyılda endüstri devrimiyle başlamış, 21 . yüzyılda ise dijital devrimle birlikte göz ardı edilemeyecek bir noktaya ulaşmış olan bu kopma, makale kapsamında, mimarlığ toplumdan; yani, toplumsal değerler, dinamikler, gerçekler ve önceliklerden gittikçe uzaklaştırmış olduğu için eleştirilmiştir.

Diğer yandan, tüm bu eleştiriler, gösteri mimarlığının ve gösteri toplumunun bugün olduğu gibi gelecekte de varlığını güçlendirerek sürdüreceği gerçeğini değiştirmeyecektir. Çünkü bunları var eden politik, ekonomik ve sosyolojik koşullar ile teknolojik olanaklar her geçen gün daha da güçlenmektedir. Bununla birlikte, mimarlar, tasarımcılar, politik ve ekonomik gücü elinde bulunduranlar ve toplumu oluşturan bireyler olarak bizim için imgesel etki ya da gösteri değil toplumsal yarar öncelikli olmalıdır. Yine de, içinde bulunduğumuz bu dönemde gösteriden kaçamadığımıza göre, mimarlık ve toplum ile üretim ve tüketim arasındaki ilişkileri yeniden düzenlememiz gerekmektedir. Bunun için, üretimi ve tüketimi arttırmak yerine her ikisini de dengede tutmak önemlidir. Mimarlığı ise bireysel hırslardan, kazançtan ve gösteri aracı olmaktan uzaklaştırıp yeniden topluma yarar sağlamayı önceleyen bir üretim alanı haline getirmek gerekir. Belki de böylece bugünün mimarlığında ve toplumunda abartılmış ve aşırılaştırılmış olan gösteri ehlileştirilebilir• 


\section{Kaynakça}

Adorno, T. (2020). Kültür endüstrisi kültür yönetimi. (Çev. N. Ülner, M. Tüzel, E. Gen). İstanbul: İletişim Yayınları. (Orijinal yayın tarihi, 1972)

Baudrillard, J. (2008). Tüketim toplumu. (Çev. H. Deliceçayl1, F. Keskin). İstanbul: Ayrıntı Yayınları. (Orijinal yayın tarihi, 1970)

Colomina, B. (1988). On architecture, production and reproduction. B. Colomina (Ed.), Architectureproduction içinde (6-23. ss.). New York: Princeton Architectural Press.

Debord, G. (1996). Gösteri toplumu. (Çev. A. Ekmekçi, O. Taşkent). İstanbul: Ayrıntı Yayınları. (Orijinal yayın tarihi, 1967)

Deleuze, G. (1997). Cinema 1: The movement image. (Çev. H. Tomlinson, B. Haberjam). Minneapolis: University of Minnesota Press. (Orijinal yayın tarihi, 1983)

Dyckhoff, T. (2017). The age of spectacle: Adventures in architecture and the 21st century city. New York: Random House Books.

Frampton, K. (1996). Modern architecture: A critical history. London: Thames and Hudson.

Galiano, L. F. (2005). Spectacle and its discontents; or, the elusive joys of architainment. W. S. Saunders (Ed.), Commodification and spectacle in architecture: A Harvard design magazine reader içinde (1-7. ss.). Minnesota: University of Minnesota Press.

Güleç, G. (2019). Mimarlık imgeleri, kent ve ekonomi: Hamburg Filarmoni örneği. IV. Uluslararas1 Kent Araştırmaları Kongresi'nde sunuldu, Kent Araştırmaları Enstitüsü, Ankara. 16-18 Ekim 2019.

Hartoonian, G. (2012). Architecture and spectacle: A critique. Farnham: Ashgate Publishing.

Leatherbarrow, D. ve Mostafavi, M. (2002). Surface architecture. London: The MIT Press.

Pallasmaa, J. (2011, a). Tenin gözleri: Mimarlık ve duyular. (Çev. A. U. Kılıç). İstanbul: YEM Yayınları. (Orijinal yayın tarihi, 1996)

Pallasmaa, J. (2011, b). The embodied image: Imagination and imagery in architecture. New York: Wiley \& Sons Publishers.

Pallasmaa, J. (2016). Matter, hapticity and time: Material imagination and the voice of matter. Building Material, (20), 171-189.

Rattenbury, K. (2002). This is not architecture: Media constructions. New York: Routledge.

Saunders, W. S. (2005). Preface. W. S. Saunders (Ed.), Commodification and spectacle in architecture: A Harvard design magazine reader içinde (vii-viii. ss.). Minnesota: University of Minnesota Press.

Sorkin, M. (2005). Brand aid; or, the lexus and the Guggenheim (further tales of the notorious B.I.G.ness). W. S. Saunders (Ed.), Commodification and spectacle in architecture: A Harvard design magazine reader içinde (22-33. ss.). Minnesota: University of Minnesota Press.

Urry, J. (1999). Mekânları tüketmek. (Çev. Rahmi G. Öğdül). İstanbul: Ayrıntı Yayınları. (Orijinal yayın tarihi, 1995)

Virilio, P. (1991). The aesthetics of disappearance. Los Angeles: Semiotext(e) Publishers.

Wigley, M. (1998). The architecture of atmosphere. Daidalos Architecture, (68), 18-27.

Yırtıcı, H. (2005). Çăgdaş kapitalizmin mekânsal örgütlenmesi. İstanbul: İstanbul Bilgi Üniversitesi Yayınları.
URL-1 https://www.archdaily.com/33238/national-library-in-astana-kazakhstan-big [Erişim tarihi 17 Ekim 2021]

URL-2 https://www.artsy.net/guggenheim-bilbao [Erişim tarihi 17 Ekim 2021]

URL-3 http://www.aliartun.com/yazilar/mimarin-sohret-duskunlugu-emre-arolat-ve-guy-debord/ [Erişim tarihi 17 Ekim 2021]

URL-4 https://www.architectural-review.com/architects/ empty-gestures-starchitectures-swan-song [Erişim tarihi 17 Ekim 2021]

URL-5 https://www.designboom.com/architecture/zaha-hadid-opus-dubai-laurian-ghinitoiu-05-06-2020/ [Erişim tarihi 17 Ekim 2021]

URL-6 https://designwanted.com/architecture/mad-architects/ [Erişim tarihi 17 Ekim 2021]

URL-7 https://www.archdaily.com/796345/allmannajuvet-zinc-mine-museum-peter-zumthor [Erişim tarihi 17 Ekim 2021]

URL-8 https://ivisare.com/projects/417581-zaha-hadid-architects-virgile-simon-bertrand-seven7panda-changsha-meixihu-international-culture-arts-centre [Erişim tarihi 17 Ekim 2021] 